\section{Towards a better understanding of patient perspectives of clinical teaching in ophthalmology}

DG Ezra, T Salam, PM Sullivan and N Okhravi

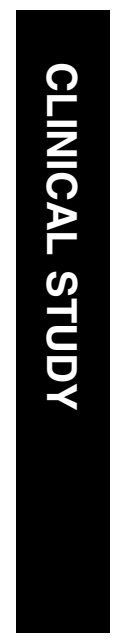

\begin{abstract}
Objective To investigate of the perspectives of ophthalmology patients involved in clinical teaching.

Methods In all, 26 patients attending a revision course for postgraduate Membership of the Royal College of Ophthalmologists examination were recruited. Every patient was examined by each of 36 residents who were present on this course making a total of 936 clinical examinations. Patient perspectives on their experience were investigated using a questionnaire. Four domains were investigated: interpersonal aspects, information exchange, discomfort, and overall perceptions.
\end{abstract}

Results Four different examinations were carried out: neurological, orthoptic and slit-lamp examination of the anterior or posterior segment. The overwhelming proportion of patients learned much about their condition and felt that their contribution towards the training was valuable. Patients found the experience to be positive and satisfying, and all of the patients expressed a desire to reattend. No significant difference in patient discomfort $(P=0.36)$ or perceptions of rough handling by doctors $(P=0.62)$ between patients undergoing slit-lamp examination or non-slit-lamp examination was evident. Conclusions Patients are willing to participate in clinical teaching and assessment, and they gain from the experience. Patients undergoing examinations using high luminance light sources were no more affected by discomfort than those undergoing eye movement or neurological examinations. Our data demonstrate the argument for a greater role of patient-based teaching as a training and assessment tool for fundoscopy.

Eye (2009) 23, 1681-1684; doi:10.1038/eye.2008.332; published online 7 November 2008
Keywords: fundoscopy; clinical teaching; patient

Introduction

Osler ${ }^{1}$ described medicine as an art and science that should be taught at the bedside. In 1903, in an open letter to the medical profession, he emphasised the need for patient-based clinical teaching. He wrote 'for the junior student in medicine and surgery, it is a safe rule to have no teaching without a patient for a text and the best teaching is taught by the patient himself'. However, over the course of the 20th century, a trend has been observed whereby general clinical teaching had moved from the bedside to the conference room. ${ }^{2}$ The belief that patients would find medical terminology unfathomable and uncomfortable is thought to have underpinned this migration. ${ }^{3,4}$

Against this background, much ophthalmology teaching takes place in the conference room. The reasons for this are complex. Firstly, many of the diagnostic skills required in ophthalmology are based on pattern recognition and these skills lend themselves to picture-based teaching. This has been facilitated in recent years by the development of technologies allowing for high-definition digital fundus photography, slit-lamp video and ease of data transfer. Furthermore, there has been a perception unique to ophthalmology that the examination process of fundoscopy using a high-luminance light source is in itself painful and uncomfortable.

Although there has been investigation into patient perspectives on clinical teaching in general medical and surgical clinical teaching, ${ }^{4-7}$ there has been, to our knowledge, no investigation of the perspectives of ophthalmology patients involved in clinical teaching.
Department of Education, Moorfields Eye Hospital, London, UK

Correspondence: DG Ezra, Department of Education, Moorfields Eye Hospital, London EC1V 2PD, UK Tel: + 07815732 455; Fax: + 02082025383 . E-mail: d.ezra@ ucl.ac.uk

Received: 24 September 2008

Accepted in revised form: 29 September 2008 Published online: 7 November 2008

Financial support: None This paper has not, in whole or part, been submitted elsewhere at present 


\section{Materials and methods}

This study was undertaken in the setting of a revision course for postgraduate Membership of the Royal College of Ophthalmologists final examination. This is a 2-week course based at Moorfields Eye Hospital in London. A total of 36 junior residents were present on this course. Although this course is mainly lecture based, two consecutive clinical teaching days are included. The course is designed to provide a selection of both rare and common ophthalmic conditions, which trainees are likely to encounter in their clinical examinations. Patients were recruited to this course on an informal basis over the preceding 2-3 weeks. Patients attending clinics run by the course organisers were asked whether they would like to participate. A small honorarium was paid to each participant to cover their transport costs. Every patient was examined by each trainee who were quizzed or taken through the clinical signs of the patient by one of the teaching staff. After the course, a questionnaire was completed by all of the patients to assess their perspectives of their experiences on this teaching course. Four domains were specified: interpersonal, information exchange, discomfort, and overall perceptions. We certify that the institutional and governmental regulations concerning the ethical use of human volunteers were followed in this research.

\section{Results}

A total of 26 patients attended on the clinical teaching days and each patient was examined by the 36 course attendees making a total of 936 clinical examinations. Patient characteristics are shown in Table 1. The average age of the patients was 53 years, with $42 \%$ women and $58 \%$ men. Most patients were mobile enough to attend the hospital independently. Only $27 \%$ needed hospital transport. Four different types of examination were carried out: neurological, orthoptic, slit-lamp (anterior segment), and slit-lamp (posterior segment). The distributions of these examinations and the types of diagnoses are summarised in Table 2.

Table 1 Patient characteristics

\begin{tabular}{ll}
\hline Patient characteristics & \\
\hline Age & Mean 53 years \\
& SD (19.6) \\
Gender & Male 58\% (15) \\
& Female 42\% (11) \\
Race & White British 62\% (16) \\
Mobility (transport needed?) & Other 38\% (10) \\
\hline
\end{tabular}

The results of all questions from the four defined domains are summarised in Table 3. Overall, patients found doctors to be respectful and were kept well informed. The overwhelming proportion of patients

Table 2 Examination groups

\begin{tabular}{lcl}
\hline $\begin{array}{l}\text { Examination } \\
\text { type }\end{array}$ & $\begin{array}{c}\text { Number of } \\
\text { patients }\end{array}$ & Diagnoses \\
\hline Neurological & $23 \%$ (6) & $\begin{array}{l}\text { Multiple sclerosis, peripheral } \\
\text { neuropathy, parkinsons } \\
\text { disease, cerebellar stroke, and } \\
\text { friedrichs ataxia }\end{array}$ \\
Orthoptic & $15 \%$ (4) & $\begin{array}{l}\text { Fourth nerve palsy, exophoria, } \\
\text { consecutive exotropia, and } \\
\text { sixth nerve palsy }\end{array}$ \\
Slit lamp (anterior & $19 \%$ (5) & $\begin{array}{l}\text { Keratoconus, corneal } \\
\text { dystrophies, endothelial } \\
\text { kegment) }\end{array}$ \\
keratoplasty, and herpes \\
zoster ophthalmicus \\
Diabetic retinopathy, \\
Slit lamp \\
(fundoscopy)
\end{tabular}

Table 3 Questionnaire details

\begin{tabular}{|c|c|}
\hline Questionnaire item & $\begin{array}{l}\text { Patients answering } \\
\text { affirmatively }\end{array}$ \\
\hline \multicolumn{2}{|l|}{ Interpersonal } \\
\hline Did doctors introduce themselves well? & $100 \%(26)$ \\
\hline Did doctors treat you with respect? & $100 \%(26)$ \\
\hline $\begin{array}{l}\text { Were you kept waiting longer than } \\
\text { expected? }\end{array}$ & $4 \%(1)$ \\
\hline $\begin{array}{l}\text { Were you kept informed of the } \\
\text { procedures? }\end{array}$ & $65 \%(17)$ \\
\hline \multicolumn{2}{|l|}{ Information exchange } \\
\hline I learned much about my condition & $73 \%(19)$ \\
\hline $\begin{array}{l}\text { I feel of value to help train the next } \\
\text { generation of eye doctors }\end{array}$ & $100 \%(26)$ \\
\hline $\begin{array}{l}\text { I helped the doctors to understand more } \\
\text { about my condition }\end{array}$ & $96 \%(25)$ \\
\hline \multicolumn{2}{|l|}{ Discomfort } \\
\hline $\begin{array}{l}\text { Doctors were rough during the } \\
\text { examination }\end{array}$ & $4 \%(1)$ \\
\hline Level of discomfort ${ }^{\mathrm{a}}$ & $\begin{array}{l}\text { Mean } 1.25 \\
\text { SD } 0.4\end{array}$ \\
\hline \multicolumn{2}{|l|}{ Overall } \\
\hline Experience was positive and satisfying & $100 \%(26)$ \\
\hline Experience caused worry & $46 \%(12)$ \\
\hline $\begin{array}{l}\text { Would be happy to attend another } \\
\text { teaching session }\end{array}$ & $100 \%(26)$ \\
\hline $\begin{array}{l}\text { Would be happy to attend an } \\
\text { examination for multiple candidates }\end{array}$ & $100 \%(26)$ \\
\hline
\end{tabular}


Table 4 Perceptions of discomfort

\begin{tabular}{lccc}
\hline & Slit lamp & Non-slit lamp & P-value \\
\hline Mean discomfort score & 1.25 & 1.1 & $P=0.36 t$-test \\
Doctors were rough during the examination & $7 \%(1)$ & $0 \%(0)$ & $P=0.62$ (fisher's exact test) \\
\hline
\end{tabular}

learned much about their condition and felt that their contribution towards training was valuable. Very little discomfort was perceived by patients undergoing examinations with a mean discomfort score of mean 1.2 (SD, 0.4) as measured by a 4-point Likert scale. Overall, patients found the experience to be positive and satisfying, and all patients expressed a desire to reattend and also a willingness to take part in clinical examinations in a similar setting.

Discomfort parameters were also analysed to identify any differences between patient undergoing slit-lamp illumination (anterior segment or fundoscopy $n=16$ ) and patients undergoing all other types of examination (neurological and orthoptic, $n=10$ ). No significant difference in patient discomfort or perceptions of rough handling by the doctors was evident (see Table 4).

\section{Discussion}

Patient perspectives on their role in clinical ophthalmology teaching are consistent with a body of literature concerning bedside teaching in other areas of medicine where it is well established that patients generally learn more about their condition and enjoy the experience. ${ }^{8,9}$ It is also well established that patients find the experience satisfying and positive and feel that they contribute significantly to the doctors' education and understanding of the disease. ${ }^{3}$

The observation that $46 \%$ of patients experienced worry despite a generally positive experience is a curious one. Many of the patients on the course have long-term chronic progressive conditions and this may simply be a reflection of general anxieties and concerns over the progression of their condition.

Of additional interest is the finding that patients undergoing slit lamp examinations were no more affected by discomfort than those undergoing eye movement or neurological examinations. There have been concerns raised in the past that ophthalmology patients should not be used for formal examinations or clinical teaching as the high-intensity light needed for fundoscopy may be unpleasant. Accordingly, a considerable amount of clinical teaching and assessment, particularly for undergraduates, makes use of simulated eye models. ${ }^{10}$

However, simulation models are not fully realistic and their construct validity has never been assessed. Our findings showed that patients undergoing ophthalmic examinations with high-luminance light sources did not experience any significant additional discomfort and all of the patients reported a positive experience and expressed a willingness to take part in future teaching sessions or examinations. Our data demonstrate the argument for a greater role of patient-based teaching as a training and assessment tool for fundoscopy.

Importantly, there have been numerous reports of retinal phototoxicity after exposure to operating microscope lights. However, the effect is related to prolonged surgery and any visual impairment is usually transient. ${ }^{11}$ Important exceptions to this are the rare rodcone dystrophies where the possibility of light causing retinal injury has been shown in animal models. ${ }^{12}$

An additional point of interest is the quality of resident learning obtained from direct patient examination $v s$ examination through digital platforms. This is a particularly important consideration, as modalities for arriving at diagnosis and therapeutic decisions may be changing. Although it is doubtful that the clinical skills of direct patient examination will ever be eclipsed by remote examination technology, the ideal mixture of the two in resident education is a subject that needs constant monitoring.

Despite the relatively small number of patients (26), the total number of clinical examinations in this study was much larger (936). The results convey a clear message that although other teaching modalities are important, patients are willing to participate in clinical teaching and assessment and that they gain from the experience. This may also be important for clinical teaching in other specialities where examinations have typically been perceived as uncomfortable. Further research in this area is needed to better elucidate the benefits that patient-based teaching offers to both trainees and patients.

\section{References}

1 Osler W. On the need of a radical reform in our methods of teaching senior students. Med News 1903; 82: 49-53.

2 Shankel SW, Mazzaferri EL. Teaching the resident in internal medicine. Present practices and suggestions for the future. JAMA 1986; 256(6): 725-729.

3 Rogers HD, Carline JD, Paauw DS. Examination room presentations in general internal medicine clinic: patients' and students' perceptions. Acad Med 2003; 78(9): 945-949. 
4 Payson HE, Barchas JD. A time study of medical teaching rounds. N Engl J Med 1965; 273(27): 1468-1471.

5 Nair BR, Coughlan JL, Hensley MJ. Student and patient perspectives on bedside teaching. Med Educ 1997; 31(5): 341-346.

6 Anderson RJ, Cyran E, Schilling L, Lin CT, Albertson G, Ware $\mathrm{L}$ et al. Outpatient case presentations in the conference room versus examination room: results from two randomized controlled trials. Am J Med 2002; 113(8): 657-662.

7 Lehmann LS, Brancati FL, Chen MC, Roter D, Dobs AS. The effect of bedside case presentations on patients' perceptions of their medical care. N Engl J Med 1997; 336(16): 1150-1155.

8 Linfors EW, Neelon FA. Sounding boards. The case for bedside rounds. N Engl J Med 1980; 303: 1273-1275.
9 Fletcher KE, Rankey DS, Stern DTJ. Bedside interactions from the other side of the bedrail. Gen Intern Med 2005; 20(1): 58-61.

10 Bradley P. A simple eye model to objectively assess ophthalmoscopic skills of medical students. Med Educ 1999; 33(8): 592-595.

11 Knox Cartwright NE, Tole DM, Haynes RJ, Males JJ, Dick AD, Mayer EJ. Recovery from macular phototoxicity after corneal triple procedure. Cornea 2007; 26(1): 102-104.

12 Vaughan DK, Coulibaly SF, Darrow RM, Organisciak DT. A morphometric study of light-induced damage in transgenic rat models of retinitis pigmentosa. Invest Ophthalmol Vis Sci 2003; 44(2): 848-855. 